\title{
THE JU /'HOANSI WAY OF HUNTING LARGE ANIMALS
}

The Ju/'hoan hunters had a preference, during the 50s, for the search of large animals. Such a preference could have been the same that drove hunters in the last 50 thousand years to hunt large animals until their extinction.

\section{Osvaldo Nestor Herrera}

Independent researcher

e-mail: onherrera@protonmail.com

SUMMARY - About the loss of many genera of large mammals in the last 50 thousand years worldwide, the hypothesis of animal extinction due to overkill arose in the 60s. According to the defenders of this hypothesis, the results of overkill were rapid extinctions or extinctions that occurred after a slow population decline, depending on animal vulnerability. I revisit ethnographic studies with Ju/'hoan hunter-gatherers, made between the 50s and 70s, to inquire about their ways of hunting large animals in a region of the Kalahari in southern Africa. The Ju/'hoan hunters capture a great diversity of animal species but have a preference for large animals, even when they are not easy to hunt, because they contribute to the survival of all the members of each camp. In my opinion, the ethnographic information strengthens the idea of the importance of hunting large animals for the groups of anatomically modern humans that expanded out of Africa after 100 ka ago.

KEYWORDS - Overkill hypothesis, Ju/'hoan hunter-gatherers.

\section{INTRODUCTION}

Hunting by ancient hunters began to be considered a possible cause of extinction since the coexistence of humans with now-extinct animal species was recognized. As from the late 60s, Paul Martin was the main defender of the hypothesis of animal extinction due to overkill (Cohen 2002), the loss of the haft of 200 genera of large mammals (those weighing more than 45 kilograms) in the last 50 thousand years worldwide (Martin 2005).

According to Paul Martin, the global pattern of extinctions favors the hypothesis of overkill as the most probable cause, which he develops very well in his last book, Twilight of the mammoths (2005). In Martin's essay, the emphasis is on finding large prey that were easy to track, find and hunt, resulting in their rapid extinction (Martin 2005).

Chris Johnson also develops a clear exposition of the hypothesis of animal extinction due to overkill in his main text, Australia's Mammal Extinctions (2006). Johnson considers the disappearance of species that 
occurred in Australia, where the extinctions cut deeper into the fauna, leaving nothing above 45 kilograms alive (Johnson 2006). In Johnson's essay, the emphasis is placed on easy access to prey which, due to its slow reproduction and lower capacity for population recovery (characteristics of marsupial mammals), was more sensitive to small increases in mortality, resulting in a slow population decline until their extinction (Johnson 2006).

According to Martin and Johnson, the results of overkill were rapid extinctions, or extinctions that occurred after a slow population decline long after the arrival of the first human hunters, respectively. Both alternatives can be the extremes in a complex spectrum of possibilities (Johnson 2006). The intensity of hunting and the ability to recover the population size, make up the main variables that determined the rate of population decline of each species until their extinction. The vulnerability of animal species is at the center of the scene of the general hypothesis of extinction due to overkill.

The initial goal of this work is to inquire about the hunting methods of the Ju/'hoansi in a region of the Kalahari, one of the more isolated parts of the arid savanna in southern Africa during the 20th century. Ju/'hoansi speak a !Kung dialect, so that that they were referred to as !Kung people in the publications from the 50s to 70s (Wadley et al. 2015). The Ju/'hoan hunter-gatherers maintain traditional hunting and gathering practices and have recently contributed to ethnoarchaeological research focused on their arrow making techniques (Wadley et al. 2015). I revisit ethnographic information that allows understanding the reasons that prompted the Ju/'hoan hunters to search for large prey in Africa, a continent where large animal species abound, mainly large antelopes. Africa kept its animal diversity almost intact, with few records of animal extinctions in the last thousand years (Martin 2005). In this sense, I try to answer the questions: do hunters have a preference for large animals? why?

The final goal of this work is to reconsider the hypothesis of animal extinction due to overkill in relation to the ethnographic information revisited, also taking into account relevant archaeological information.

\section{THE JU /'HOAN HUNTER-GATHERERS}

The Marshall family began in 1950 a series of expeditions for an ethnographic study with Ju/'hoan nomadic hunter-gatherer groups. The Ju/'hoan hunter-gatherers numbered around a thousand people during the 50s, preserving a traditional way of life in the Nyae-Nyae area (South-West Africa, later Namibia) and in the Dobe area (Botswana), a region of the Kalahari in southern Africa (Marshall 1976).

Lorna Marshall, her husband Laurence, and their two children, Elizabeth and John, were present in some of the eight expeditions that would take place until 1961 in the Nyae-Nyae area. During this lengthy encounter, the Marshall family was integrated into the daily life of the hunters achieving an unusual intimacy. With the academic results of her ethnographic work, Lorna Marshall published The !Kung of Nyae Nyae (1976).

Richard Lee and Irven DeVore began in 1963 another ethnographic study with Ju/'hoan hunter-gatherers in the Dobe area, focused heavily on ecology (Lee 1976). With the results of a large group of researchers from various disciplines, members of the Harvard Kalahari Research Group of the University of California, 
Richard Lee and Irven DeVore published Kalahari Hunter-Gatherers (1976).

Ju/'hoan families join together and form bands on the basis of consanguinity and affinity. One of these relationships links every individual to a family, each family to another family in a band and each family to another family across band demarcations (Marshall 1976).

In the Kalahari, there must be a permanent or semi-permanent waterhole at which the band who inhabit the territory base themselves in the dry season. The band (n/ / abesi), the grouping above the family, is the unit in which families combine to live together in groups of viable size. A Ju/'hoan speaks of his territory (n!ore), as the place in which he lives or to which he belongs (Marshall 1976). A lifestyle focused on sustaining peaceful ties allows them to share a waterhole among various bands:

«!Kung bands have an entity that is visible to the eye. When the band encamps, the members cluster their fires together. If more than one band inhabits a territory and the bands encamp near the same waterhole, or if bands are visiting and are encamped near their hosts, the bands maintain a distinct separation. We had an unusually good opportunity to observe this particular characteristic during the drought of 1952 when five bands encamped themselves around the /Gam waterhole. »

(Marshall 1976: 179)

The animal diversity in this region of the Kalahari is important and hunters systematically hunt various species of mammals and birds. (Yellen et al. 1976). Three species of large antelope, kudu (Tragelaphus strepsiceros), wildebeest (Connochaetes taurinus) and gemsbok (Orix gazella), weighing more than $180 \mathrm{~kg}$ for males and $100 \mathrm{~kg}$ for females, are frequently hunted with poisoned arrows:

«The big antelopes, kudu, wildebeest and gemsbok are regularly hunted with poisoned arrows, but a good hunter feels he has done well if he kills as many as six of these in a year. The general scarcity of game and their frequency of movement raises obvious difficulties for !Kung hunters. Except in a very rough way, it is rarely possible to predict on a day to day basis where the big antelopes will be located. »

(Yellen et al. 1976: 39)

«Typically, in the course of following an animal, a working hypothesis as to his position or condition will be advanced and then tested continually against the spoor. For example, Konner accompanied a man returning from an unsuccessful kudu hunt. It was early afternoon. They began following a gemsbok spoor which, 
the man said, was made the same morning. After about twenty minutes the man stooped and said, "No, it was made last night,” and abandoned the spoor. Asked what made him change his mind, he indicated a single gemsbok hoof print with a mouse track inside it, that is, superimposed on it. Since mice are nocturnal, the gemsbok print must have been left during the night. »

(Blurton Jones et al. 1976: 342)

Nicolas Blurton Jones and Melvin Konner, members of the Harvard Kalahari Research Group, organized six discussion groups (“seminars”) on Ju/'hoan knowledge of animal behavior with five or six hunters at each group, revealing much familiarity with the behavior of each animal species:

«Evidence that knowledge of behavior is closely related to its applied value comes from many statements made during the seminars. In discussing fighting of kudu, one man described the sound one hears of their horns crashing, and how, if one hears the sound, one can approach to shoot them. The same man, a very enthusiastic and busy hunter also described how one tracks infant kudu, showing that it sleeps away from its mother, and that one can follow it to where it is hidden, and kill it by hitting it. In telling us how wildebeest infants follow their mothers soon after birth, they said that one cannot catch the infants because they follow their mothers so soon. But in the same seminar people described the way in which the kudu mother returns and calls the fawn, which then runs out to joint her to feed, and how the mother never goes to the place where the infant sleeps, a degree of detail which seems hardly necessary if one is simply trying to shoot mother or baby. »

(Blurton Jones et al. 1976: 340-1)

In the Kalahari, several species of mammals take refuge in burrows, where they are captured. The biggest of them, the warthog (Phacocoerus africanus), weighing more than $60 \mathrm{~kg}$ for males and $45 \mathrm{~kg}$ for females, is one of the most frequently hunted. The hunting technique used varies a bit according to each species:

«An unorthodox but highly effective hunting technique is the probing of underground burrows. Four important species are taken this way. The springhare is killed with a flexible 4-meter pole with a metal hook at the end. These nocturnal animals sleep in long narrow burrows by day. The hunter finds an occupied burrow, probes it with the pole until he has hooked his prey, and then excavates the soft sand until he can retrieve the animal. The large African porcupine is also an underground dweller which the !Kung hunt. They often light a fire at the burrow 
mouth in an attempt to half-suffocate the animal and drive it from the burrow. Sometimes they dig down on the den from above, or actually crawl down the narrow burrow to spear the occupant. The ant bear (up to $65 \mathrm{~kg}$ ) also lives in burrows, and men dig down on the prey from above to spear it. Finally, warthogs, when run to ground, are flushed from their holes by lighting a fire at the entrance and then speared when trying to escape. The underground species are highly desired because they are very fat, and animal fat is one of the elements most scarce in the San diet»

(Yellen et al. 1976: 39)

During the 50s, the largest Ju/'hoan group consisted of 47 people. The hunters' concern being the search for large animals that can feed all the members of a camp, thus contributing to the survival of the group:

«Their principal hunting time and purposeful endeavor was given to the search for the big animals. Infrequently the hunters tried to dig out an aardvark, sleeping by day in its burrow, or to prod out springhare from their holes with hooks hafted to long flexible poles. They gladly shot duikers, steenboks, porcupines, geese, or paouw if they saw them. However, if they found spoor of the big animals fresh enough to encourage them, they would follow it and not deliberately search for the small animals. »

(Marshall 1976: 134)

The custom of sharing the meat of big animals hunted by hunting parties, also includes a not very large antelope like springbok (Antidorcas marsupialis), weighing 30 kg males and females:

«Small mammals, the size of the duikers or smaller, and birds belong to the man who shoots or snares them. Tortoises, lizards, grasshoppers, and snakes are picked up incidentally by anyone and belong to the person who picks them up. That person may share his find only with his or her immediate family or with others as he or she chooses, in the way plant foods are shared. ... the custom of meat-sharing applies to the big animals which are deliberately hunted by hunting parties: eland, kudu, gemsbok, wildebeest, hartebeest, springbok, warthog, and ostrich»

(Marshall 1976: 295-6)

The owner of the animal is the owner of the first arrow to be effectively shot into the animal so that it penetrates enough for its poison to work. That person is responsible for the distribution. There may be 
several hunters in the hunting party and several arrows in the animal, but this seems to cause no confusion or conflict. Every arrow is known and the hunters can see which first penetrates effectively so that its poison could account for the kill. Each hunter gets a share of the meat anyway (Marshall 1976).

The first distribution the owner makes is to the hunters and to the giver of the arrow, if the arrow was not one the owner made himself. The meat, always uncooked in the first distribution, is given on the bone unless the animal is so large that the meat has been cut into strips at the kill (Marshall 1976).

In a second distribution, the several persons who got meat in the first distribution distribute it further. This meat is also given uncooked. A man's first obligation is to give his wife's parents the best he has in generous portions while still fulfilling other primary obligations, which are to his own parents, his spouse, and his offspring (close kinship) (Marshall 1976).

Everyone who receives meat gives again, in another wave of sharing, to his or her parents, parents-in-law, spouse, offspring, siblings, and others. The meat may be cooked and the quantities small. The result of the distribution is that everybody gets some meat (Marshall 1976). The idea of sharing the meat obtained through hunting is deeply rooted, with full awareness of the benefits by generating reciprocal engagement, an important role in sustaining peaceful ties, dissolving any tensions that could exist, and restoring heartiness among members:

«The !Kung are quite conscious of the value of meat-sharing and they talk about it, especially about the benefit of the mutual obligation it entails. The idea of sharing is deeply implanted and very successfully imposes its restraints. To keep meat without sharing is one of the things that just is not done. »

(Marshall 1976: 302-3)

The principal hunting time of the Ju/'hoan hunters is the search for the big animals. The big antelopes, because they go without drinking for long periods, do not come regularly to waterholes, they roam anywhere in the land, are widely scattered, singly or in herds of a few animals. When the hunters find spoor of the big animals, they follow it. The big antelopes are regularly hunted with poisoned arrows. The custom of meatsharing applies to the big animals which are deliberately hunted by hunting parties and the result is that everybody gets some meat (Marshall 1976).

\section{THE ARCHAEOLOGICAL EVIDENCE}

Out of Africa, few archaeological sites give hints about the preferences for hunting animals by early groups of anatomically modern humans. The human remains of the Uluzzian layers of Grotta del Cavallo belonged to the oldest known European anatomically modern humans in southern Europe, dated 45-43 ka ago (Benazzi et al. 2011). The two deciduous molars attributed to anatomically modern humans are associated 
with blade and bladelet lithic assemblages, personal ornaments in the form of marine shell beads, worked bone, and colorants (Benazzi et al. 2011; Benazzi 2012). The systematic use-traces analysis of 146 backed lithic pieces indicates that the main function of these Uluzzian pieces was hunting, as part of mechanically delivered projectiles (Sano et al. 2019).

Faunal remains from Grotta del Cavallo indicate more intensive exploitation of young horses at the Uluzzian layers, in relation to the Mousterian layers. Considering that young horses are protected by stallions, the intensive hunting of young horses could reflect skilled long-range hunting in the Uluzzian (Sano et al. 2019). The researchers of the site suggest that modern humans equipped themselves with new projectile technology when they migrated into Europe at around 45 ka ago (Sano et al. 2019). Based on use-traces (micro-residues and fractures) analysis, there is strong evidence for the use of bow and arrow (bone-tipped and stone-tipped arrows) technology at Sibudu Cave (in South Africa), more than 60 ka ago (Lombard et al. 2012; Backwell et al. 2018).

\section{CONCLUSION}

In the Kalahari, the search for large prey begins with the search for their spoor. The amount of spoor depends on the number of animals that are at that moment in the place. The animal density of each species forms a variable that influences its capture probability. When the density of a species decreases, the predation pressure on it also decreases. Predation relationships based on chance encounters allow prey to avoid extinction because when their population size decreases, the probability of encountering the predator also decreases. For the extinction of an animal species, there must have been, in addition to a proper hunting technique, an insistent search for it, sustaining hunting pressure even with a low population density of the prey until its definitive disappearance. Animal vulnerability remains the key to account for the extinction of species due to overkill.

The Pinnacle Point archaeological site, a sea cave on the south coast of Africa (Marean et al. 2007), provides strong evidence that early humans displayed key elements of modern behaviors as far back as $165 \mathrm{ka}$ (McBrearty et al. 2007). Some researchers believe that modern cognitive capacity emerged at the same time as modern anatomy and that various aspects of human culture arose gradually over the course of subsequent millennia, shaping a package of modern human behaviors in Africa (McBrearty et al. 2007).

The formation of kinship networks and norms for the acceptance of marriages around the prohibition of incest is universal in today's hunter-gatherer societies. (Lévi-Strauss 1969 [1949]). To my knowledge, no one has suggested yet when the emergence of kinship relations occurred. I suggest that modern human behaviors and kinship relationships developed simultaneously in Africa. If this was so, the human groups that expanded outside Africa were already structured according to kinship relationships, probably forming groups as numerous as the ethnographically known hunter-gatherer groups. According to this assumption, the ethnographic information about the Ju/'hoansi strengthens the idea of the importance that hunting of large animals could have had for the groups of humans that expanded out of Africa after 100 ka ago. 
The Ju/'hoan hunters capture a great diversity of animal species but have a preference for large animals. Anatomically modern humans that dispersed out of Africa across the planet may have had a similar general preference for large animals. In addition to size, the ease of locating and hunting each animal species, they could define specific preferences in the search for animals, determining the intensity of overhunting of each species in the past.

Hunting for large animals such as horses is antique and dates as far back as $300 \mathrm{ka}$ (Conard et al. 2015). The preference for large animals could have been a permanent motivation for the trial and adoption of new hunting technologies, such as the of bow and arrow in southern Africa (Lombard et al. 2012; Backwell et al. 2018) and the spear thrower at around 19 ka ago in western Europe (Cattelain et al. 2015), that allowed more accurate hunting while keeping a greater distance from potentially dangerous prey. Hunting young horses by Uluzzian hunters could be a clue to the preferences of the first groups of anatomically modern humans in Europe for hunting large animals.

\section{BIBLIOGRAPHY}

Backwell L, Bradfield J, Carlson KJ, et al (2018) The antiquity of bow-and-arrow technology: evidence from Middle Stone Age layers at Sibudu Cave. Antiquity 92 362:289-303

Benazzi S, Douka K, Fornai C, et al (2011) Early dispersal of modern humans in Europe and implications for Neanderthal behaviour. Nature 479:525-528

Benazzi S (2012) The first modern Europeans. Journal of Anthropological Sciences 90:1-4

Blurton JN, Konner MJ (1976) !Kung Knowledge of Animal Behavior (or: The Proper Study of Manking Is Animals). In: Lee, RB, DeVore I (eds) Kalahari Hunter-Gatherers: Studies of the !Kung San and The Neighbors, Harvard University Press, Cambridge, Massachusetts and London

Cattelain P, Pétillon J (2015) “Type 2a”, the earliest Palaeolithic spear-thrower: a new Middle Magdalenian object from Isturitz (Pyrénées-Atlantiques, France) and its implications. Paleo 26:1-19

Cohen C (2002) The fate of the mammoth: fossils, myth and history, The University of Chicago Press, Chicago and London

Conard NJ, Serangeli J, Böhner U, et al (2015) Excavations at Schöningen and paradigm shifts in human evolution. Journal of Human Evolution 89:1-17

Johnson C (2006) Australia’s mammal extinctions: a 50,000 year history, Cambridge University Press, New York

Lee RB (1976) Introduction. In: Lee, RB, DeVore I (eds) Kalahari Hunter-Gatherers: Studies of the !Kung San and The Neighbors, Harvard University Press, Cambridge, Massachusetts and London

Lee, RB, DeVore I (1976) Kalahari Hunter-Gatherers. Studies of the !Kung San and The Neighbors, Harvard University Press, Cambridge, Massachusetts and London

Lombard M, Phillipson L (2010) Indications of bow and stone-tipped arrow use 64000 years ago in 
KwaZulu-Natal, South Africa. Antiquity 84:635-648

Leví-Strauss C (1969) The Elementary Structures of Kinship, Bell JH, Von Sturmer JR (trans), Needham R (ed), Eyre \& Spottiswoode, London [Leví-Strauss C (1949) Les structures élémentaires de la parenté, Presses Universitaires de France, Paris]

Marean CW, Bar-Matthews M, Bernatchez J, et al (2007) Early human use of marine resources and pigment in South Africa during the Middle Pleistocene. Nature 449:905-908

Marshall L (1976) The !Kung of Nyae Nyae, Harvard University Press, Cambridge

Martin P (2005) Twilight of the mammoths: ice age extinctions and the rewilding of America, University of

California Press, Berkeley and Los Angeles

McBrearty S, Stringer C (2007) The coast in colour. Nature 449:793-794

Sano K, Arrighi S, Stani C et al. (2019) The earliest evidence for mechanically delivered projectile weapons in Europe. Nature Ecology \& Evolution 3:1409-1414

Wadley L, Trower G, Backwell L et al (2015) Traditional Glue, Adhesive and Poison Used for Composite Weapons by Ju/'hoan San in Nyae Nyae, Namibia. Implications for the Evolution of Hunting Equipment in Prehistory. PLoS ONE 10, e0140269

Yellen JE, Lee RB (1976) The Dobe-/Du/da Environment. Background to a Hunting and Gathering Way of Life. In: Lee, RB, DeVore I (eds) Kalahari Hunter-Gatherers: Studies of the !Kung San and The Neighbors, Harvard University Press, Cambridge, Massachusetts and London 